\title{
O estágio supervisionado nos cursos de licenciatura da EAD/UFMS: métodos, resultados e desafios
}

Daniela S. Kawamoto Kanashiro, UFMS-GEPEAD/USP, daniela.ead.ufms@gmail.com Mirian Lange Noal, UFMS-GEPEAD, miriannoal@ gmail.com

Patrícia Graciela da Rocha, UFMS-GEPEAD/UFSC, patrigraciro@ gmail.com Sonia Burigato, UFMS-GEPEAD, soniaburigato@gmail.com

Resumo: O presente trabalho objetiva discutir as propostas de estágio vigentes dos cursos de Letras, Matemática e Pedagogia da UFMS, na modalidade a distância. Os estudos justificam-se na medida em que possibilitam a reflexão de nossa prática e nos permitem reavaliar o trabalho. A pesquisa analisa dados coletados pelo Grupo de Estudos e Pesquisa de Educação Aberta e a Distância (GEPEAD), referente às percepções do aluno e do tutor de estágio em relação à organização e desenvolvimento das atividades. Fundamentadas nas respostas de cinco questões respondidas pelos tutores e alunos, analisaremos a avaliação feita pelos envolvidos focando: a) a clareza das informações fornecidas pelo curso quanto aos objetivos, procedimentos, relatórios e avaliação de estágio; b) o apoio do tutor de estágio; c) o apoio do supervisor de estágio; d) a atuação do professor orientador; e) a contribuição do estágio para a formação pessoal e profissional. Os resultados nos indicam que, de forma geral, a experiência tem sido satisfatória e que, sobretudo nos cursos a distância, os regulamentos e as orientações precisam ser bastante claros e objetivos, visando a assegurar o cumprimento da legislação, a uniformidade de ações e a qualidade necessária a cursos de formação docente.

Palavras-chave: estágio; educação a distância; tutor; formação docente.

\section{Supervised teaching practice training in the distance education teaching undergraduation courses at UFMS: methods, results and challenges}

Abstract: This study aims at discussing the supervised teaching practice training in Letters, Mathematics and Pedagogy undergraduation courses at UFMS in the distance education modality. The relevance is the possibility of reflection of our practice as well as the evaluation of this process of teacher formation. The work investigates the collected data from the Grupo de Estudos e Pesquisa de Educação Aberta e a Distância (GEPEAD) concerning the students' and the tutors' perceptions in relation to the organization and development of the proposed activities. We intend to analyze the tutors' and students' evaluation by focusing on: (a) the information coherence concerning the objectives, proceedings, reports and training evaluation; (b) the training tutor support; (c) the training supervisor support; (d) the orientating teacher performance; (e) the training contribution to the professional and personal formation. The findings indicate that, in a general view, the experience has been satisfactory and, besides, in the distance courses, the regulations and orientations need to be clearer by aiming at making sure the legislation working, the actions uniformity as well as the quality necessary in the teacher formation.

Key-words: training; distance education; tutor; teacher formation.

\section{Introdução}

Neste trabalho pretendemos refletir sobre a implantação do estágio curricular obrigatório nos cursos de Letras Português e Espanhol, Matemática e Pedagogia oferecidos pela Coordenadoria de Educação Aberta e a Distância (CED) da 
Universidade Federal de Mato Grosso do Sul (UFMS). Para tal reflexão, descreveremos, brevemente, o funcionamento dos estágios supervisionados obrigatórios dos três cursos de licenciatura e analisaremos a avaliação realizada por alunos e tutores com base nas respostas de um questionário aplicado pelo Grupo de Estudos e Pesquisas sobre Educação Aberta e a Distância (GEPEAD).

A justificativa deste trabalho está na possibilidade de refletirmos sobre as propostas de estágio vigentes, uma vez que as percepções dos sujeitos envolvidos no processo nos permitem reavaliar nossa prática constantemente.

Cada colegiado de curso, baseado no regulamento geral de estágio, da UFMS, formula suas próprias normatizações, que fazem parte do Projeto Pedagógico dos Cursos (PPC), com o intuito de orientar todos os procedimentos e estratégias utilizadas para que o estagiário possa vivenciar a prática da sala de aula. É preciso ressaltar que nos cursos a distância essas regras precisam ser bastante claras e objetivas, além de estar amplamente divulgadas para todos os envolvidos no processo, a fim de assegurar o cumprimento da legislação, a uniformidade de ações e a qualidade necessária a cursos de formação docente.

É importante observar que, embora usando estratégias diferentes, as atividades de estágio, nos três cursos, estão organizadas de forma que o graduando, na modalidade $\mathrm{EaD}$, possa viver experiências que o permitam compreender o cotidiano de escolas que atuam na educação básica. Além disso, os cursos de licenciatura mencionados cumprem o tempo mínimo de 400 horas de prática de estágio, obedecendo ao Parecer $\mathrm{CNE} / \mathrm{CP}$ 9/2001.

\section{A Educação a Distância}

As experiências de ensino e aprendizagem na modalidade a distância são relativamente novas no Brasil. Sartori e Roesler (2005) revelam que se na segunda metade dos anos 90 constataram-se alguns casos de ensino via correspondência, rádioeducação e tele-educação, por exemplo. Entre 2002 a 2005 houve uma expansão das tele-educação por meio das tele-aulas, com o uso da TV digital, iniciando o processo de profissionalização da gestão dos programas de educação a distância. A ruptura maior se deu com a difusão da internet que consolidou o conceito da $\mathrm{EaD}$ como interatividade virtual mediada por múltiplas ferramentas de comunicação e estabelece, portanto, nova relação entre tempo e espaço. As mesmas pesquisadoras situam a inclusão da atuação das universidades brasileiras na $\mathrm{EaD}$, em caráter regular, a partir de 1994 "[...] ]quando a Universidade Federal de Mato Grosso criou um curso de licenciatura para formar professores leigos no exercício do magistério nas séries iniciais do ensino fundamental [...]" (SARTORI, ROESLER, 2005, p. 11).

Embora seja bastante complexo antecipar o que acontecerá com as modalidades de ensino e aprendizagem, Moran (2004) afirma que é possível antever algumas perspectivas para a educação:

O foco dos cursos será cada vez mais na aprendizagem significativa, na aprendizagem conjunta, não tanto olhar um conteúdo predeterminado. Haverá cursos prontos, com autores consagrados, com apresentações multimídia, mas predominarão os cursos com interação, debate, desenvolvimento conjunto de experiências, projetos, solução de problemas, com uso intensivo de tecnologias interativas audiovisuais e apoio on-line. [...] Não armazenaremos tanta informação em casa. Guardaremos só o essencial e acessaremos a qualquer momento o que precisarmos (o custo será decrescente). 
Diante de novos contextos de ensino e aprendizagem e de novas necessidades, procuraremos neste artigo relatar o desenvolvimento do estágio supervisionado nos cursos de licenciatura e alguns aspectos relacionados à percepção de alunos e tutores envolvidos no processo.

Os estágios supervisionados, obrigatórios nos cursos de formação de professores, representam um desafio para os docentes que são responsáveis pela elaboração e pelo acompanhamento da proposta, bem como para os alunos. No caso específico da modalidade a distância, esse desafio se estende para os tutores e professores supervisores que atuam nas instituições escolares. Embora as diretrizes nacionais definam que as práticas precisam acontecer desde o início dos cursos de licenciatura, os estágios ainda são os tempos e os espaços que possibilitam, de fato, o encontro do aluno com a sua futura profissão. Assim, na visão de Pimenta (1997, p. 21) os estágios são "[...] as atividades que os alunos deverão realizar durante o seu curso de formação, junto ao futuro campo de trabalho". O encontro, proporcionado pelos estágios, entre alunos de cursos de graduação com os professores da educação básica, possibilita oportunidades ímpares de ensino e de aprendizagem por meio de trocas de saberes mediados pela universidade. (PIMENTA; LIMA, 2004)

Considerando o exposto, recai sobre os estágios a responsabilidade de proporcionar experiências vividas que assegurem novos significados para a docência: "[...] estágio como um elemento fundamental na formação profissional e como um dos espaços privilegiados para a formação do docente na concepção do professor críticoreflexivo e na constituição dos saberes docentes necessários." (LEITE; GHEDIN e ALMEIDA, 2008, p. 33)

No entanto, considerando que o aluno da $\mathrm{EaD}$, de maneira geral, é também um trabalhador, há uma série de dificuldades para a realização de estágios que, de fato, permitam a experiência de estar e de atuar nas instituições educativas sem aligeiramentos, pois, como alerta Fávero (1992, p. 65): “[...] não é só freqüentando um curso de graduação que um indivíduo se torna profissional." Soma-se a esse contexto, a memória que esses alunos, futuros professores, têm de seus processos de escolarização, na maioria das vezes, tradicionais e pouco eficazes no processo de despertar para o estudo, para a busca do conhecimento, para a pesquisa.

A realidade dos estágios nos cursos presenciais ainda está calcada nas etapas de: observação, planejamento, docência. Os estágios na modalidade a distância, inclusive o desenvolvido na EaD/UFMS, ainda têm muita semelhança com esse tradicional formato. No entanto, considerando que a $\mathrm{EaD}$ vem desconstruindo tantos paradigmas, esperamos que também possa contribuir para ressignificar os estágios nos cursos de formação de professores, pois, como afirma Fazenda (1991, p. 61), é possível transformar a educação apesar de reconhecer que : "[...] existam vários bloqueios ao nosso trabalho, desde o de ordem política, até as questões burocrático-administrativas, penso que é dever da Universidade discutir com a rede de ensino algumas experiências desenvolvidas em seu âmbito".

\section{Operacionalização do Estágio Supervisionado obrigatório nos cursos de licenciatura da EAD/UFMS}

A Coordenadoria de Educação Aberta e a Distância (CED/UFMS), em parceria com a Universidade Aberta do Brasil (UAB), atende a três programas de formação de professores (licenciaturas): UAB I (2008-2012); UAB II (2009-2013); UAB III (20102014). Fazem parte desse sistema os cursos de: Biologia; Letras (Português e Espanhol); Matemática e Pedagogia. O curso de Biologia não foi incluído neste artigo porque a 
primeira oferta fez parte do Consórcio Setentrional e foi concluída antes de a pesquisa ser aplicada. As turmas atuais do curso de Biologia fazem parte da UAB II e da UAB III e ainda não iniciaram os estágios obrigatórios. Outro recorte efetivado, para fins da apresentação e discussão dos resultados da pesquisa, foi o de considerar as turmas que fazem parte da UAB I, que têm a sua conclusão prevista para julho de 2012 e que estão desenvolvendo os estágios.

Atualmente a UAB I conta com quatrocentos e setenta e cinco (475) alunos estagiários matriculados nos cursos de Letras (Português e Espanhol), Matemática e Pedagogia. Os estágios, nos cursos de licenciatura, são coordenados por uma Comissão de Estágio (COE), formada por representantes docentes e um representante discente com o objetivo de planejar, coordenar, validar e avaliar os estágios. A operacionalização está sob a responsabilidade de uma equipe que atua a distância e presencialmente, composta por: a) professores orientadores, do quadro efetivo da UFMS, são responsáveis pela organização e acompanhamento de todas as etapas do estágio (planejamento, elaboração de materiais, indicação de referencial teórico, orientação e avaliação); b) tutores de estágio, atuantes em cada polo de apoio presencial, têm a atribuição de acompanhar, orientar e avaliar os alunos em todas as etapas do estágio; c) professores supervisores, profissionais pertencentes ao quadro de pessoal da instituição campo, são os responsáveis pelo acompanhamento direto dos estagiários nas etapas desenvolvidas no local de estágio em parceria com os tutores de estágio; d) tutores a distância e tutores presenciais, responsáveis por auxiliar, quando solicitados, a equipe de estágio e os alunos.

Os estágios obrigatórios, atendendo à legislação educacional, iniciam na segunda metade do curso e perfazem um total de 400 horas. Cada curso organiza os estágios obrigatórios com autonomia e de acordo com o seu PPC, distribuindo proporcionalmente o total da carga horária obrigatória.

A seguir, descreveremos, sucintamente, a proposta de estágio das três licenciaturas da EaD/UFMS.

\section{a) Letras Português e Espanhol}

O acadêmico do curso de Letras com habilitação em Português e Espanhol deve cumprir cinco etapas do estágio obrigatório: a) Estágio Supervisionado em Língua Portuguesa I; b) Estágio Supervisionado em Língua Portuguesa II; c) Estágio Supervisionado em Literatura; d) Estágio Supervisionado em Língua Espanhola I; e) Estágio Supervisionado em Língua Espanhola II. Em cada etapa o estagiário deve perfazer a carga horária de $85 \mathrm{~h}$, totalizando $425 \mathrm{~h}$.

O Estágio Supervisionado em Língua Portuguesa I, em Língua Espanhola I e II foram desenvolvidos nos cinco polos de apoio presencial da UAB I. No total contam com seis tutores de estágio supervisionado, cinco professores orientadores (docentes efetivos da instituição) e aproximadamente cem (100) estagiários. Já os da UAB II têm, no total, cinco tutores de Estágio, quatro professores orientadores - os mesmos atuantes na UAB I - e cerca de oitenta discentes.

É preciso destacar que em cada etapa do estágio obrigatório foram desenvolvidas atividades considerando as especificidades do nível de ensino (fundamental ou médio) e a língua (portuguesa ou espanhola). Alguns aspectos, porém, são recorrentes em todas as etapas e obrigatórias a todos os estagiários:

- o estágio supervisionado acontece na cidade onde está localizado o polo de apoio presencial; 
- em cada etapa o primeiro encontro acontece presencialmente, garantindo as orientações iniciais e esclarecimento de dúvidas, assim como estudo de texto teórico e atividade escrita;

- são propostas atividades a distância com atividades a serem postadas no Moodle, conforme questões previamente estabelecidas;

- antes de o estagiário desenvolver o conteúdo previsto, acontecem as simulações das aulas na presença dos colegas, do tutor e do professor orientador. $\mathrm{O}$ grupo analisa a aula de um acadêmico, comenta, sugere alterações e/ou outras propostas de atividades;

- os acadêmicos ministram aulas, sejam nos cursos regulares ou em forma de minicurso;

- os estagiários apresentam um relatório final, na conclusão de cada etapa, desenvolvendo as partes indicadas no GDA;

- os acadêmicos passam pela socialização de experiência, ao final de cada estágio, interagindo com seus pares por meio do blog (estagiosupervisionadoletras.blogspot.com).

Também garantimos o uso das novas tecnologias quando os acadêmicos gravam microaulas, por meio do Adobe Connect, referentes a aspectos teóricos do ensino e aprendizagem de línguas estrangeiras, no Estágio Supervisionado em Língua Espanhola I. Posteriormente o material é divulgado pelo Moodle e os estagiários podem interagir, ainda que de forma assíncrona, com os colegas de outros polos. Também recorrendo às novas tecnologias, no Estágio Supervisionado em Língua Espanhola II, é promovido um seminário virtual para discussão síncrona de aspectos relacionados à implantação do espanhol no Ensino Médio, nas provas do Enem e sobre a compreensão leitora em língua estrangeira e instrumentos de avaliação para esta habilidade.

O trabalho de elaboração de planos de aula e de material para ser utilizado em sala tem o acompanhamento do professor orientador do grupo. A regência nas escolas é avaliada pelos tutores de Estágio e pelos professores supervisores.

\section{b) Matemática}

O estágio do curso de Matemática está dividido em duas etapas: a) Estágio Curricular no Ensino Fundamental (200h); b) Estágio Curricular no Ensino Médio (200h). Atualmente o estágio está acontecendo em 11 polos, sendo que sete deles são de UAB I e quatro de UAB II.

Os sujeitos envolvidos nas atividades de estágio são: sete professores orientadores (docentes do quadro da UFMS) responsáveis pelas atividades e orientações dos estagiários; professores supervisores de estágio (professor da escola), responsáveis pelo acompanhamento direto do acadêmico na prática de suas atribuições na instituição campo, e onze tutores de estágio que acompanham os acadêmicos no desenvolvimento das atividades. Enquanto os tutores presenciais acompanham os alunos em todas as disciplinas, os tutores de estágio são responsáveis especificamente pelas questões relacionadas ao desenvolvimento do estágio.

Contudo, todos os tutores são estimulados a trabalhar em conjunto quando estão ocorrendo as disciplinas de Práticas de Ensino de Matemática III e IV, pois o estágio obrigatório no curso de Licenciatura em Matemática tem como proposta proporcionar aos acadêmicos a articulação entre a teoria e a prática. Desse modo, as atividades sugeridas visam a favorecer reflexões sobre as ações com o intuito de melhorar a ação pedagógica. 
As disciplinas de Prática de Ensino em Matemática I, II, III e IV são ministradas desde o primeiro ano do curso e são planejadas para contribuir com o estágio. Principalmente nas duas primeiras, os alunos adquirem experiência em preparar aulas e seminários para apresentarem ao professor e tutor presencial.

No início da disciplina é realizado um encontro, presencial ou a distância, entre o professor orientador, o tutor de estágio e os alunos, em que são apresentadas as orientações de como deve ser realizado o estágio. Os alunos são orientados a fazerem um caderno para registrar tudo $\mathrm{o}$ que acontece durante $\mathrm{o}$ estágio e eles são acompanhados pelo tutor em todas as atividades realizadas nas escolas, bem como, no polo de apoio presencial.

O estágio no curso de Matemática proporciona, aos alunos, experiências no Ensino Fundamental e no Ensino Médio. Buscamos apresentar a docência no contexto ampliado da escola, extrapolando a sala de aula. Dessa forma, os tempos e os espaços do Estágio I e II - Ensino Fundamental e Médio, respectivamente - estão organizados em:

- Sala de aula: observação, participação, planejamento e regência;

- Laboratório de Ensino de Matemática: preparo de oficinas e de seminários;

- Atividades gerais: encontros presenciais, elaboração dos relatórios parciais e finais.

Além da regência estão previstos os seminários que são elaborados a partir de temas do Ensino Fundamental ou Médio e sorteados entre os alunos que preparam e apresentam ao professor orientador e ao tutor de estágio no final do semestre.As oficinas são realizadas com base nos temas sugeridos pelo supervisor de estágio juntamente com a coordenação pedagógica da escola, conforme suas necessidades. Geralmente a escolha é feita em função das dificuldades dos alunos em determinado conteúdo ou projetos em andamento na escola. Essas oficinas são ministradas aos alunos das escolas em horários diferenciados.

\section{c) Pedagogia}

O estágio supervisionado no curso de Pedagogia está sendo desenvolvido em dez polos de apoio presencial e envolve: duzentos e oitenta e seis alunos; quinze tutores de estágio; quinze tutores a distância; quinze tutores presenciais; seis professoras orientadoras; uma coordenadora de tutores; uma secretária. A estrutura curricular prevê três estágios obrigatórios: Estágio Supervisionado na Educação Infantil (150 horas); Estágio Supervisionado nos Anos Iniciais do Ensino Fundamental (150 horas); Estágio Supervisionado em um núcleo de aprofundamento a ser escolhido pelos alunos: Educação de Jovens e Adultos ou Estágio Supervisionado nas Instituições Especializadas e nos Serviços de Apoio Especializados ou Estágio Supervisionado em Gestão Escolar (100 horas).

A estrutura curricular prevê três estágios obrigatórios: Estágio Supervisionado na Educação Infantil; Estágio Supervisionado nos Anos Iniciais do Ensino Fundamental; Estágio Supervisionado em um núcleo de aprofundamento a ser escolhido pelos alunos: Educação de Jovens e Adultos ou Estágio Supervisionado nas Instituições Especializadas e nos Serviços de Apoio Especializados ou Estágio Supervisionado em Gestão Escolar.

O estágio supervisionado, após o cumprimento dos trâmites legais, envolve as seguintes etapas: a) o preparo didático-pedagógico (leituras, debates, registros, redação de textos); b) a visita a instituições educativas (pesquisa exploratória e diagnóstica); c) o preparo para a docência (planejamento e confecção de materiais); d) a docência 
(considerada a etapa mais significativa); e) a elaboração do relatório com as memórias do estágio (registro processual); f) a participação no seminário final (apresentação oral e mostra de materiais). Todas as etapas são orientadas por um professor, docente do quadro da UFMS, supervisionadas pelos tutores de estágio e pelos professores supervisores, com colaboração dos tutores presenciais e a distância.

A concepção político-pedagógica fundamenta o estágio como uma construção processual, em diálogo com as instituições campo, com o objetivo de construir pontes de articulação entre teoria e prática, na busca da síntese (que é sempre temporal, questionável, mutável) e da práxis contextualizada. Nesse sentido, deve ser construída uma maneira respeitosa e compartilhada de chegar e de estar nas instituições educativas.

A atuação em dupla tem sido estimulada, pois se compreende que a ação pedagógica é política e coletiva. Precisamos nos educar e fazer o esforço, intencional, de atuar em conjunto, já que a marca da escolarização tem sido, de maneira geral, o reforço ao individualismo. Por isso, pretendemos que uma das contribuições do estágio seja a de proporcionar a experiência do pensar, do planejar e do atuar compartilhados para que seja possível perceber e respeitar a diversidade e a subjetividade inerentes a qualquer grupo social.

Os estagiários são estimulados a utilizar o caderno de campo para registrar as observações efetivadas, as experiências, as aprendizagens, as reflexões, as dúvidas, os sentimentos e as emoções. Essa recomendação aponta para a constituição de profissionais pesquisadores e para a possibilidade do estágio supervisionado tornar-se campo de pesquisa e, talvez, tema do Trabalho de Conclusão de Curso (TCC). Assim, no exercício da escrita, como meio de organizar os pensamentos e as experiências, a elaboração do relatório final, que se constitui nas memórias do estágio, perpassa todas as etapas e exige do aluno o zelo e o arquivamento de todas as atividades avaliativas depois de efetivadas as correções recomendadas e/ou exigidas pelo avaliador.

Ao final do estágio, como atividade de culminância e de encerramento, é realizado um seminário, para que todos os protagonistas apresentem e compartilhem suas experiências, avaliações e expectativas no exercício do fazer comprometido e contextualizado. O seminário, para melhor cumprir com a função política, pedagógica e social do estágio, deve contar com a participação de representantes das instituições que foram campos de estágio e ser aberto para a comunidade. No entanto, resguardados os limites e considerando as possibilidades do polo, é assegurada autonomia para cada equipe de estágio organizar e definir a amplitude do evento. Paralelamente ao seminário, é organizada uma mostra com as memórias do estágio (materiais, relatórios, depoimentos, fotos, banner, livros e outros).

Esperamos que o estágio faça emergir as lacunas da formação universitária, provoque o debate e a autoavaliação, suscitando em cada aluno a necessidade e o desejo de estudar para acrescentar conhecimentos essenciais e significativos a uma atuação profissional comprometida, investigativa, sempre em processo, sempre passível de transformação.

\section{Material e métodos}

Esta pesquisa está inserida no projeto "A Educação a Distância na Universidade Federal de Mato Grosso do Sul: Implantação, Bases Teóricas, Processos e Resultados”, registrado no $\mathrm{CNPq}$, que tem por objeto de investigação a implantação e a implementação da Educação a Distância na UFMS, desenvolvido por professores e profissionais da Coordenadoria de Educação a Distância, com os objetivos de registrar e analisar as origens dessa modalidade de ensino na referida instituição, as bases teóricas que sustentam suas práticas, sua forma de funcionamento $\mathrm{e}$ os seus principais 
resultados, visto que o desenvolvimento da $\mathrm{EaD}$ nesta instituição está articulado com a execução de importantes políticas públicas da educação superior, e sua investigação implica no acompanhamento dessas políticas.

O projeto está subdividido em três grandes eixos: 1) registro da implantação da $\mathrm{EaD}$, bases teórico-metodológicas e propostas pedagógicas; 2) sujeitos envolvidos no desenvolvimento da $\mathrm{EaD}$; 3) gestão, avaliação e modelo de desenvolvimento de $\mathrm{EaD}$ e está sendo realizado em quatro etapas: a) Etapa bibliográfica e exploratória; b) Etapa de coleta e tratamento de documentos; c) Etapa de coleta e tratamento dos dados coletados em campo; d) Sistematização dos resultados e elaboração do relatório final.

A presente pesquisa está inserida no eixo 2 - "Sujeitos envolvidos no desenvolvimento da EaD" - que pretende caracterizar o perfil socioeconômico e a formação profissional dos alunos, professores (efetivos e colaboradores), tutores (locais e a distância) e gestores (profissionais que atuam na CED e nos polos, coordenando processos) e a percepção dos mesmos sobre os processos e resultados desenvolvidos nos cursos da EaD. Para isso, desenvolvemos instrumentos on-line (disponibilizados no Moodle) de avaliação que buscam detectar a percepção dos sujeitos mencionados acima sobre três dimensões: recursos humanos e alunos(as), organização didático-pedagógica e infraestrutura (física e tecnológica).

Para cada dimensão, há aspectos a serem analisados na seguinte escala de qualidade: Muito bom; Bom; Regular; Fraco e Péssimo. Para os casos em que não há condições de avaliação, há a opção "Não foi possível avaliar". Após essa avaliação objetiva, fica a disposição do sujeito da pesquisa um campo para comentar cada dimensão. A adesão à pesquisa é voluntária e os membros participantes assinam um termo de consentimento livre e esclarecido que nos autoriza usar os dados para pesquisa.

Os dados utilizados para este trabalho são resultados de respostas dadas por alunos e tutores de estágio a seis perguntas da dimensão didático-pedagógica que se referiam ao estágio supervisionado, são elas:

1. Como você avalia a clareza das informações fornecidas quanto aos objetivos, procedimentos, relatórios e avaliação do estágio?

2. Como você avalia o apoio do(a) tutor(a) de estágio para o preparo e o desenvolvimento das atividades do estágio?

3. Como você avalia o apoio do supervisor de estágio (professor(a) do ensino fundamental/médio da escola que acompanha as atividades do estagiário)?

4. Como você avalia a atuação do(a) professor(a) orientador(a) de estágio (professor(a) efetivo(a) da UFMS responsável pela organização e acompanhamento do estágio)?

5. Como você avalia a contribuição do estágio para a sua formação profissional e pessoal?

6. Como você avalia a participação e/ou o interesse dos alunos das escolas durante as aulas de estágio supervisionado?

A partir dessas perguntas, obtivemos 407 respostas dos alunos de Letras Português e Espanhol, Matemática e Pedagogia, das quais consideraremos apenas as respostas dos alunos de UAB I que estão realizando $\mathrm{s}$ atividades de estágio supervisionado há mais tempo, pois grande parte dos alunos de UAB II respondeu que "não foi possível avaliar" a maioria das perguntas, isso porque se encontravam em fase inicial das atividades de estágio quando responderam as questões do questionário. Sendo assim, será objeto da nossa análise a resposta de 64 alunos do curso de Matemática, 209 alunos da Pedagogia, 75 alunos de Letras, totalizando 348.

\section{Resultados e discussão}

V. $9 \mathrm{~N}^{\mathrm{o}} 2$, dezembro, 2011 

a seguir:

Nesta parte da pesquisa analisaremos as respostas dos alunos e tutores tabulados Tabela 1 - Percentual das respostas dos alunos e dos tutores

\begin{tabular}{|l|c|c|c|c|c|c|c|c|c|c|c|c|}
\hline \multirow{2}{*}{} & \multicolumn{2}{|c|}{ Muito bom } & \multicolumn{3}{|c|}{ Bom } & \multicolumn{2}{c|}{ Regular } & \multicolumn{2}{c|}{ Fraco } & \multicolumn{2}{c|}{ Péssimo } & \multicolumn{2}{c|}{$\begin{array}{c}\text { Não foi } \\
\text { possível } \\
\text { avaliar }\end{array}$} \\
\cline { 2 - 16 } & Aluno & Tutor & Aluno & Tutor & Aluno & Tutor & Aluno & Tutor & Aluno & Tutor & Aluno & Tutor \\
\hline Questão 1 & $31 \%$ & $55 \%$ & $41 \%$ & $45 \%$ & $13 \%$ & - & $5 \%$ & - & $4 \%$ & - & $6 \%$ & - \\
\hline Questão 2 & $39 \%$ & - & $37 \%$ & - & $8 \%$ & - & $4 \%$ & - & $5 \%$ & - & $7 \%$ & - \\
\hline Questão 3 & $33 \%$ & $60 \%$ & $37 \%$ & $40 \%$ & $7 \%$ & - & $1 \%$ & - & $1 \%$ & - & $21 \%$ & - \\
\hline Questão 4 & $36 \%$ & $65 \%$ & $37 \%$ & $20 \%$ & $10 \%$ & $15 \%$ & $2 \%$ & - & $1 \%$ & - & $14 \%$ & - \\
\hline Questão 5 & $67 \%$ & - & $23 \%$ & - & $4 \%$ & - & $0,2 \%$ & - & - & - & $5,8 \%$ & - \\
\hline Questão 6 & - & $35 \%$ & - & $45 \%$ & - & $5 \%$ & - & $5 \%$ & - & - & - & $10 \%$ \\
\hline
\end{tabular}

Sobre a primeira pergunta - Como você avalia a clareza das informações fornecidas quanto aos objetivos, procedimentos, relatórios e avaliação do estágio? aproximadamente $28 \%$ das respostas dos estagiários oscilaram entre regular a não foi possível avaliar. Isso nos leva a afirmar que nem todas as orientações feitas pelo professor orientador e pelo tutor de estágio foram claras o suficiente para eliminar as dúvidas. Por outro lado, na percepção dos tutores, não observamos nenhuma resposta diferente de muito bom e bom.

Com relação à segunda questão - Como você avalia o apoio do(a) tutor(a) de estágio para o preparo e o desenvolvimento das atividades do estágio? - perto de $17 \%$ das respostas também compreenderam entre regular a não foi possível avaliar. Embora $83 \%$ considerem o trabalho do tutor satisfatório, ainda é possível identificar que há falhas de comunicação na modalidade a distância, mesmo entre os protagonistas que têm a possibilidade do encontro presencial. É importante esclarecer que os tutores de estágio não responderam esta questão, uma vez que a autoavaliação não foi prevista na pesquisa.

Sobre a pergunta 3 - Como você avalia o apoio do supervisor de estágio (professor(a) do ensino fundamental/médio da escola que acompanha as atividades do estagiário)? - 30\% dos acadêmicos, conforme respostas assinaladas, evidenciam que não conhecem ou não estão satisfeitos com o desempenho do professor supervisor. $O$ dado mais preocupante é que $21 \%$ responderam não ser possível avaliar esse profissional. Uma hipótese é a de que alguns alunos, sobretudo os do curso de Pedagogia, no momento em que responderam o questionário ainda não estavam desenvolvendo atividade na instituição campo e, portanto, é possível que não tivessem ainda estabelecido contato com o professor supervisor. Observamos que esta hipótese requer maior investigação.

Com relação à quarta questão - Como você avalia a atuação do(a) professor(a) orientador(a) de estágio (professor(a) efetivo(a) da UFMS responsável pela organização e acompanhamento do estágio)? - aproximadamente $27 \%$ dos alunos responderam entre regular e não foi possível avaliar a atuação do professor orientador. Esse dado indica que a atuação do professor precisa ser repensada, pois ele atua no planejamento, na preparação dos materiais, na elaboração do GDA, por meio de videoconferência e, em alguns casos, presencialmente na abertura da disciplina, nas aulas simuladas e no acompanhamento da regência. Nesse sentido, tem papel fundamental na condução das atividades de estágio e julgamos que este dado também exige estudos mais aprofundados sobre as reais causas das lacunas na atuação do professor orientador, ainda que mais de $70 \%$ tenha avaliado positivamente o desempenho deste profissional.

Sobre a quinta pergunta - Como você avalia a contribuição do estágio para a sua formação profissional e pessoal? - 90\% dos acadêmicos avaliaram a experiência de 
forma válida, dado significativo e satisfatório considerando que podemos ter professores bastante motivados. Cabe esclarecer que o tutor não respondeu essa questão, uma vez que consideramos que caberia apenas ao acadêmico, de forma muito reflexiva e individual, avaliar a contribuição do estágio para sua formação profissional e pessoal. Dessa forma, optamos por outra questão para contrapor os resultados das respostas como veremos a seguir.

Apenas os tutores responderam a última questão - Como você avalia a participação e/ou o interesse dos alunos das escolas durante as aulas de estágio supervisionado? - já que não consideramos a autoavaliação, ou seja, aluno avaliando o próprio aluno. Selecionamos esta questão para confrontar com os dados relacionados nas respostas dos tutores e averiguamos que $80 \%$ das respostas evidenciam a participação e/ou interesse dos alunos nas escolas durante as aulas de estágio supervisionado, o que nos indica empenho dos acadêmicos em sua formação acadêmica.

\section{Conclusões}

Ainda que os resultados da pesquisa não nos apresentem dados conclusivos sobre alguns aspectos, sinalizam pontos fortes e fracos no desenvolvimento das atividades de estágio supervisionado obrigatório nos três cursos de licenciatura da UFMS, na modalidade a distância. Tanto as respostas dos alunos quanto as dos tutores evidenciam que as experiências foram satisfatórias, embora também indiquem aspectos a serem compreendidos. Com relação à quinta questão, por exemplo, a avaliação positiva dos acadêmicos comprova que os objetivos da disciplina foram alcançados, uma vez que $90 \%$ deles afirmaram que as distintas etapas e atividades de estágio contribuíram para sua formação profissional e pessoal. Contudo, é preciso repensar formas de esclarecer as informações sobre os procedimentos, relatórios e avaliação de estágio e de consolidar o apoio do supervisor, do tutor e do professor orientador de estágio.

\section{Referências bibliográficas}

BRASIL. Lei $n^{o} 11.788$, de 25 de setembro de 2008: Dispõe sobre o estágio de estudantes.

FÁVERO, M. L. A. Universidade e estágio curricular: subsídios para discussão. In: ALVES, N. (Org.) Formação de professores: pensar e fazer. São Paulo: Cortez, 1992. p.53-71.

FAZENDA, I. C. A. O papel do estágio nos cursos de formação de professores. In: PICONEZ, S. C. B. (org.). A prática de ensino e o estágio supervis ionado. Campinas: Papirus, 1991.

LEITE, Y. U. F.; GHEDIN, E.; ALMEIDA, M. I. Formação de professores: caminhos e descaminhos da prática. Brasillia: Liber Livro Editora, 2008.

MORAN, J. M. Perspectivas (virtuais) para a educação. Mundo Virtual. Cadernos Adenauer IV, $n^{\circ}$ 6. Rio de Janeiro, Fundação Konrad Adenauer, abril, 2004, páginas 3145.

PIMENTA, S. G.; LIMA, M. S. L. Estágio e docência. 2. ed. São Paulo: Cortez, 2004.

PIMENTA, S. G. O estágio na formação de professores: unidade teoria e prática. 3. ed. São Paulo: Cortez, 1997. p. 21 - 80. 
SARTORI, A.; ROESLER, J. Educação Superior a Distância: gestão da aprendizagem e da produção de materiais didáticos impressos e on-line. Tubarão: Ed. Unisul, 2005. 